\title{
ORIENTAÇÕES PARA O ESTUDO DOS HIEROİ LÓGOI DE ARISTIDES: COMPOSIÇÃO, EDIÇÕES, TRADUÇÕES
}

\section{Lolita Guimarães Guerra*}

RESUMO: A composição dos Hieroì Lógoi de Élio Aristides (c. 170 E.C.), debatida pela historiografia e pelos estudos clássicos, sinaliza elementos importantes sobre sua especificidade em meio à totalidade dos discursos do autor. A partir da tradição retórica e por meio do gênero da aretalogia e da autobiografia, o autor pretende oferecer um discurso autêntico e enaltecer Asclépio, deus ao qual se oferece como devoto, como paciente e como pupilo. Neste artigo, com o interesse de instrumentalizar o aprofundamento das investigações em torno dessa obra ainda pouco estudada no Brasil, apresentamos um extenso levantamento de seus manuscritos, edições e traduções. Além disso, discutimos alguns problemas relevantes sobre sua condição enquanto documento histórico, principalmente em torno de sua identidade e dos processos de sua composição.

PALAVRAS-CHAVE: Élio Aristides; Hieroì Lógoi; documentação escrita.

\begin{abstract}
The composing of Aelius Aristides' Hieroi Lógoi (c. 170 C.E.), discussed by classical studies and historiography, suggests important features regarding its specificity amongst its author's discourses. From the rhetoric tradition, aratology and autobiography, Aristides intends to offer an authentic discourse and praise Asclepius, god to whom he offers himself as devotee, patient and pupil. This article attempts offer some intelectual instruments as an attempt to contribute to wider investigations on the Hieroi Logoi, still little studied in Brazil. Therefore, we render offer an extensive survey of its manuscripts, editions and translations. We also discuss some relevant issues related to its condition as a historical document, particularly regardings its identity and composition processes.
\end{abstract}

KEYWORDS: Aelius Aristides; Hieroì Lógoi; written source. 


\section{Aristides E OS HIEROİ LÓGOI}

$\mathrm{O}$ s Hieroi Lógoi do orador Élio Aristides consistem em seis discursos, organizados na década de 170, ${ }^{1}$ a combinar autobiografia, relatos oníricos e de viagens, reflexões profissionais, exaltações devocionais e experiências extraordinárias. ${ }^{2}$ Em resposta às ordens de Asclépio recebidas em sonhos por seu autor, eles consistem numa obra de exaltação oferecida a ele, como os exvotos depositados em seus santuários frequentados por devotos em busca de curas. Original da Mísia Oriental, Aristides cresceu em um meio social privilegiado e estudou com personalidades importantes em centros culturais de destaque, como Cláudio Herodes em Atenas, Alexandre de Cotieu e Antônio Pólemon em Esmirna e Cláudio Arístocles em Pérgamo (Behr, 1986, p. 1). Seus negócios e atividades intelectuais e religiosas concentravam-se basicamente nas cidades de Esmirna e Pérgamo, e em sua terra natal próxima dali. ${ }^{3} \mathrm{O}$ contexto da composição dos Hieroì Lógoi é, portanto, a Ásia Menor sob dominação romana em um período marcado pela promoção das cidades gregas orientais e por um amplo projeto de urbanização (Cortés Copete, 1995, p. 1). Adoecido na década de 140, ele passa dois anos no Asclepeion de Pérgamo. Esse período de internação e tratamento, sua cátedra, é caracterizado por um misto de devoção, cura e aprendizagem sob a condução de Asclépio (HL 2.70; 3.44). Aristides também viaja para os santuários do deus em Epidauro, no Peloponeso, e em Esmirna, na margem oriental do Egeu. Nesse cenário, os Hieroi Lógoi resultam dos encadeamentos da história de vida de Aristides: sua formação intelectual, suas más condições de saúde, sua devoção crescente em direção a Asclépio e sua percepção de ser um favorito do deus. O gênero literário da obra é, por isso, dual: ela figura simultaneamente como uma aretalogia e uma autobiografia (Cortés Copete, 1999, p. 248; Israelowich, 2012, p. 26). O lugar da obra em meio à tradição literária de exaltação e devoção aos deuses é sinalizado por André Boulanger (1923, p. 163-171), André Festugière (1952, p. 85-104), Stephen Harrison (2000), Alexia Petsalis-Diomidis (2010), Cortés Copete (1999) e Marie-Henriette Quet (1993). Os dois últimos, ao lado de Jacques Bompaire (1993) e Laurent Pernot (2006b), também destacam seu caráter autobiográfico. A leitura dos Hieroi Lógoi nesse sentido remonta a Georg Misch (1907). Em vão ele buscava nas autobiografias antigas as 'histórias das almas' de seus autores, mas tornou-se referência sobre o assunto

\footnotetext{
${ }^{1}$ Salvo quando indicado, todas as datas referem-se à Era Comum. Neste artigo, elas acompanham o levantamento anteriormente feito por Guerra, 2014, p. 40-57.

2 Chamamos de 'extraordinárias' experiências não exclusivas ao campo sobrenatural, mas cuja excepcionalidade ultrapassa a esfera mundana cotidiana e deixa como marca afetiva a comoção, o estranhamento e o maravilhamento.

3 Quanto ao local do nascimento de Aristides, os especialistas dividem-se em favor de Adriani e de Adrianuteras, cidades formalizadas por Adriano após sua visita à região, na década de 120 . $\mathrm{O}$ favorecimento a Adriani é iniciado por Filóstrato (Vida dos Sofistas, 581), seguido por Behr (1986, p. 1), Schröder (1986, p. 9), Downie (2008a, p. 182) e Cortés Copete (1995, p. 2). Adrianuteras é favorecida por Festugière (1986, p. 25) e Nicosia (1984, p. 11).

${ }^{4}$ Neste artigo, as referências aos Hieroì Lógoi encontram-se na forma abreviada, HL.
} 
e seu olhar influenciou autores como Festugière (1952, p. 97) e Peter Brown (1993, p. 43), bastante reativos à personalidade de Aristides. ${ }^{5}$ Esses autores parecem esperar da obra sua adequação a um ideal moderno da autobiografia como uma 'história da interioridade', algo que em nenhum momento Aristides se comprometeu a oferecer (Perkins, 1992, p. 249). Porém, em meio ao movimento da Segunda Sofística e ao fenômeno do 'holy man', homem santo dotado de poderes sobrenaturais, ele tem pouco de excepcional (Anderson, 1994, p. 37ss, 106ss; Pernot, 2006a, p. 35). Desde Cortés Copete (1999), de fato, a historiografia tem trabalhado justamente no sentido de recuperar a especificidade do autor e da obra como parte de uma multiplicidade intrincada de circunstâncias políticas, sociais e culturais. ${ }^{6}$ O debate sobre o caráter autobiográfico dos Hieroì Lógoi deve construir um instrumental intelectual apropriado ao lançar mão das muitas contribuições teórico-metodológicas em torno das 'escritas de si'. Dentre os estudos literários, Philippe Lejeune marcou em 1996 um parâmetro importante ao caracterizar a autobiografia como uma modalidade de escrita $e$ de leitura firmada por um pacto pelo qual se assume a identidade entre autor, narrador e protagonista (2008, p. 14ss). No mesmo campo, Paul John Eakin já havia sinalizado a complexidade do problema ao identificar a autobiografia como 'invenção de si' e destacar o caráter ficcional da 'verdade' da vida, da formação da identidade e dos meios devotados à sua apresentação (1985). O aspecto ficcional do 'eu' e da escrita de si, finalmente, deve ser pensado junto ao seu caráter fragmentário e dinâmico. Em um trabalho de 1989, o historiador Giovanni Levi o destacou ao refletir sobre os momentos contraditórios da criação da identidade expostos ao historiador interessado pela documentação biográfica (1998, p. 169).

Visto que os Hieroì Lógoi são um material ainda pouco conhecido pela historiografia e pelos estudos clássicos no Brasil, traçaremos alguns pontos pertinentes ao seu status documental. O debate sobre sua construção e a forma como ora se nos apresenta é imprescindível para os encaminhamentos historiográficos em torno deles. Como passo inicial nesse sentido, situaremos o documento em termos de suas edições e traduções. Além disso, discutiremos alguns problemas relativos aos sentidos e circunstâncias de sua composição. Esta participação no debate maior em torno da obra estabelecerá orientações sobre sua identidade e a relação do texto hoje conhecido com documentos mais antigos produzidos e mencionados por Aristides como fontes parciais para sua composição.

\footnotetext{
${ }^{5}$ A observação de Werner Jaeger (1953, p. 406) sobre a postura marcadamente cristã de Misch torna necessário um posicionamento cauteloso diante de quaisquer afirmações sobre a personalidade de Aristides. Festugière, por exemplo, falou dele como impossível de ser apreciado, incrivelmente vaidoso e profundamente egoista (1952, p. 97). Mais tarde, Brown sugeriu como causa inconsciente das suas enfermidades um sentido ameaçador de superioridade oculto em sonhos e visões grandiosas (1993, p. 43). ${ }^{6}$ Além dos mencionados trabalhos de Perkins e Pernot, destacam-se também os de Janet Downie (2008a), Alexia Petsalis-Diomidis (2010) e Lolita Guerra (2014).
} 


\section{Os MAIS ANTIGOS MANUSCRITOS E AS EDIÇÕES MODERNAS DOS HIEROİ LÓGOI}

Em solo brasileiro, as últimas décadas representaram uma ampliação significativa das traduções de documentos literários clássicos diretamente para o português. Para além das gerações anteriores, nas quais se destacaram Odorico Mendes, Carlos Alberto Nunes, Eudoro de Sousa e Haroldo de Campos, hoje acompanhamos os trabalhos dos professores Flávio Ribeiro, Trajano Vieira, Tereza Virgínia Ribeiro Barbosa, JAA Torrano, Ordep Serra e Alexandre Costa. Esse empreendimento torna os estudos clássicos no país cada vez menos dependentes de traduções em línguas estrangeiras, nos casos não atendidos pelas edições portuguesas. Porém, alguns textos permanecem largamente desconhecidos em nosso território, pouco populares mesmo em países de larga tradição editorial, como os Estados Unidos da América, a Inglaterra e a França, onde, apesar de suas edições contemporâneas, os estudos sobre eles são ainda bastante restritos. Este é o caso dos Hieroi Lógoi. Uma rápida busca nos acervos das bibliotecas universitárias brasileiras ${ }^{7}$ identifica um número limitadíssimo de volumes disponíveis da obra. Na Biblioteca de Letras da Universidade Federal de Minas Gerais, encontra-se a tradução espanhola de Maria Concepción Giner Soria (1989), infelizmente, de pouco apelo acadêmico. A mesma edição é encontrada na Universidade Estadual de Campinas (Biblioteca do Instituto de Filosofia e Ciências Humanas), ${ }^{8}$ onde há também (na Biblioteca do Instituto de Estudos da Linguagem) a tradução italiana de Salvatore Nicosia (1984); a Biblioteca da Faculdade de Ciências e Letras de Araraquara, da Universidade Estadual Paulista possui a tradução espanhola de Cortés Copete (1999); ${ }^{9}$ a Biblioteca da Faculdade de Filosofia, Letras e Ciências Humanas da Universidade de São Paulo dispõe da primeira edição moderna da obra, produzida por Wilhelm Dindorf (1829), mas não de traduções. ${ }^{10}$ Portanto, em todo o território nacional, e exclusivamente no Sudeste, os Hieroi Lógoi são conhecidos por apenas quatro volumes traduzidos para as línguas espanhola e italiana, e apenas um volume da primeira edição da obra. Diante dessas limitações, e com o objetivo de ampliar os estudos sobre Élio Aristides e os Hieroì Lógoi no país, é pertinente apresentar um levantamento das edições e traduções hoje disponíveis. O acesso a esse material é imprescindível, principalmente a pesquisadores de pouco domínio do grego antigo.

Os Hieroi Lógoi são conhecidos por três manuscritos medievais preservados na Biblioteca Laurenziana, em Florença. O mais antigo e completo é o Manuscrito A (Laurentianus 60.3), datado c. 920, e escrito por João Calígrafo para Aretas, bispo de Cesareia. Aretas acrescentara os títulos, as maiúsculas e os sinais de parágrafo ao texto, além de incluir

\footnotetext{
${ }^{7}$ Foram consideradas as instituições públicas que disponibilizam catálogos online. A busca foi realizada em 03 março de 2017.

${ }^{8} \mathrm{O}$ IFCH também dispõe do volume 1 das 'obras completas' de Aristides editadas e traduzidas por Charles Behr (1973) e publicadas na coleção Loeb (Harvard University Press). A coleção não teve continuidade e, assim, não contemplou os Hieroi Lógoi.

${ }^{9}$ Além dos volumes 2 a 4 das obras completas de Aristides na coleção Gredos.

${ }^{10}$ A biblioteca possui a tradução alemã do Discurso a Roma, por Richard Klein (1981) e o volume 1 da coleção Loeb.
} 
escólios às suas margens (Quattrocelli, 2008, p. 281). Já o Manuscrito T (Laurentianus 60.8), antes datado do século XI, hoje é identificado do século XIII, talvez obra de um copista sob as ordens de Máximo Planudes, autor da Antologia Grega (Wilson, 2009, p. 254ss). O Manuscrito D (Laurentianus 60.7) seria de datação intermediária, do século XII. Além do material florentino, há o Manuscrito S (Urbinas Graecus 122), preservado na Biblioteca do Vaticano e datado do século X. Na década de 1960, Charles Behr trabalhou com os quatro manuscritos, a fim de construir uma tradução dos discursos. Ele identificou os manuscritos A e S como os de maior qualidade documental e concluiu que o conjunto era na realidade bem menos lacunar do que o editor Bruno Keil suspeitara ao estabelecer o texto em 1898; porém, fora visivelmente corrompido em um momento prematuro, devido ao uso da caligrafia uncial pelos primeiros copistas (1968, p. 205).

A filologia alemã oitocentista produziu duas edições dos Hieroì Lógoi, usadas pelos especialistas modernos. ${ }^{11}$ A mais antiga é de Karl Wilhelm Dindorf, 1829, e a mais recente é o mencionado trabalho de Keil, de 1898, cuja numeração dos discursos de Aristides é seguida pelos especialistas contemporâneos. Estes privilegiam o texto estabelecido por Keil, pouco contestado até o momento. Salvatore Nicosia chegou a caracterizar o trabalho de Dindorf como 'velho, medíocre e inteiramente superado' (1984, p. 52). De fato, ele parece quase irrelevante para os estudiosos atuais, mas observamos seu uso por Festugière ao se encontrar diante de lacunas na edição de Keil e na tradução de Behr (HL 2.33). ${ }^{12}$ Behr, por outro lado, não recorreu a ele quando considerou pertinente modificar o texto estabelecido por Keil, e assim lançou mão dos manuscritos medievais. A tradução de 1968 é acompanhada por numerosas notas a respeito dessas transformações.

As traduções dos Hieroi Lógoi hoje em uso foram produzidas entre as décadas de 1940 e 1980 e contam com estudos introdutórios, notas e comentários dos tradutores e editores, material indispensável à crítica textual e ao trabalho historiográfico. No idioma inglês, destaca-se o já mencionado trabalho de Charles Behr com tradução e estudo da obra, de 1968. Mais tarde, Behr editou com Friedrich Lenz a totalidade dos discursos de Aristides (1976) e, depois, publicou sua tradução (1981, 1986), porém sem modificar o trabalho de 1968. Antes disso, os Hieroi Lógoi haviam sido parcialmente traduzidos para o inglês, ao lado de outros discursos de Aristides, oferecidos nas mesmas condições, na volumosa Asclepius, Collection and Interpretation of the Testimonies de Emma e Ludwig Edelstein, publicada em 1945 e reeditada em 1998. O trabalho dos Edelstein perdeu prioridade em meio aos estudos anglófonos diante do de Behr, mas permanece uma coleção de referência

\footnotetext{
${ }^{11}$ Edições mais antigas, hoje superadas, foram listadas no século XIX por Thomas Frognall Dibdin (1808, p. 171-173). A primeira delas foi feita pelo médico florentino Eufrosino Bonini em 1517 e compreende todos os discursos de Aristides, salvo o quinquagésimo terceiro. A seguinte é de 1566, de Willem Canter, uma edição grega com tradução para o latim publicada na Basileia e reeditada em 1604 em Genebra com o auxílio de seu mestre Jean Dorat. Em 1722, o médico inglês Samuel Jebb publicou em Oxford uma edição também greco-latina, na qual são reproduzidas as notas de Canter. ${ }^{12}$ Festugière faz referência à edição de Dindorf em uma conferência de 1952 (Sather Lectures, Berkeley, California), publicada em 1954.
} 
para a documentação epigráfica e literária em torno do deus Asclépio. A tradução de Behr, porém, apresenta problemas editoriais consideráveis. Por exemplo, ele modifica duas passagens (HL 4.98, 100), nas quais insere o nome 'Festo', a fim de justificar suas próprias interpretações quanto a um personagem anônimo mencionado por Aristides. É justo dizer, portanto, que apesar de esta versão do texto ser utilizada de maneira inconteste por uma série de especialistas, ela deve ser lida com certa desconfiança, e sempre com o amparo de outras traduções. Em 1984, Salvatore Nicosia publicou uma tradução italiana da obra, para a qual lançou mão dos manuscritos, a fim de produzir versões alternativas à edição de Keil, por vezes também discordando das emendas de Behr. Antes dele, em 1952, o dominicano André-Jean Festugière havia traduzido para o francês os Hieroi Lógoi, publicados, no entanto, apenas após sua morte. O trabalho permaneceria intocado até 1969, quando Festugière empreendeu uma rigorosa crítica ao trabalho de Behr, e pôde então revisar a primeira versão da tradução. Mais tarde, em 1986, o também dominicano Henri-Dominique Saffrey encontrou o material de 1969 e procedeu com sua publicação, à qual acrescentou notas e comentários (1986, p. 11). A tradução de Festugière soluciona lacunas deixadas por Behr (HL 2.6, 33). A crítica de 1969 e a edição de Saffrey de 1986 nos permitem acompanhar detalhadamente suas escolhas diante dos manuscritos, das edições oitocentistas e da versão inglesa. Naquele mesmo ano foi lançada a tradução alemã de Heinrich Otto Schröder, o qual igualmente empreendeu revisões ao trabalho de Behr e apresentou alternativas à edição de Keil. Em 1999, o historiador Cortés Copete, autor de uma obra sobre Aristides publicada quatro anos antes, foi ainda mais assertivo em sua crítica a Behr. Tradutor do conjunto completo dos discursos, Cortés Copete lamentou as confusões causadas pela versão inglesa, devido à ansiedade de Behr em identificar os personagens mencionados por Aristides com indivíduos conhecidos por outros documentos. Cortés Copete sinalizou os procedimentos de Behr como 'vilania filológica' de 'consequências históricas de mui duvidosa fiabilidade' (1999, p. 277), e então contou bem mais com as edições do texto como propostas anteriormente por Nicosia, afastando-se bastante do trabalho de Behr. ${ }^{13}$

Os Hieroì Lógoi compreendem os discursos 47 a 52 dos cinquenta e três textos de Aristides conhecidos, e alguns especialistas assim os enumeram, como Edelstein e Edelstein (1945), Cortés Copete (1995), e os autores do volume editado por Brooke Holmes e William Harris (2008). No entanto, quando ocupados diretamente dos Hieroì Lógoi, como no caso de traduções específicas do texto, a maior parte dos autores prefere numerá-los independentemente do restante da obra de Aristides, dos números 1 a 6, como é o caso de Behr (1968), Festugière (1986), Nicosia (1984), Schröder (1986), Janet Downie (2008a) e Petsalis-Diomidis (2010). A numeração em separado é pertinente; porém, não se deve perder de vista o lugar da obra em meio ao conjunto maior da produção de Aristides. Mesmo os estudos de temas mais centrais nos Hieroì Lógoi (como devoção, peregrinação, sonho, medicina) não prescindem da análise dos outros discursos produzidos pelo autor,

\footnotetext{
${ }^{13}$ As traduções de Aristides presentes neste artigo seguem Cortés Copete e valem-se da consulta ao texto grego estabelecido por Keil e às traduções anteriores.
} 
onde pontualmente eles se fazem presentes, como nos dedicados e relacionados a Asclépio e outros deuses.

\section{A COMPOSIÇão dos HIEROİ LÓGOI}

Convencionamos identificar a obra por Hieroì Lógoi, e não por uma versão traduzida do título original grego, e devemos justificar tal escolha, contrária a uma tendência mais ampla, segundo a qual a obra é referida por sua forma traduzida: Discours Sacrés (Festugière, 1952, 1986), Sacred Tales (Behr, 1968; Harris, 2009; Israelowich, 2012); Discorsi Sacri (Nicosia, 1984), Heilige Berichte (Schröder, 1986), Discursos Sagrados (Soria, 1989; Cortés Copete, 1995, 1999). Privilegiar grande parte da tradição especializada e traduzir o título pode conduzir a perdas quanto aos sentidos como construídos por Aristides. Assim, o título original foi mantido pelas historiadoras Alexia Petsalis-Diomidis (2008) e Janet Downie, para a qual a tradução evoca uma interpretação limitada do complexo termo lógos, que imediatamente remete a obra à atividade retórica do autor $(2008 \mathrm{a}, 03)$. O argumento é pertinente e deve ser complementado por um olhar mais cuidadoso sobre os sentidos religiosos da obra. Festugière os sinalizara ao analisar a expressão hieròs lógos em meio ao vocabulário de narrativas sobre as origens míticas de certas interdições e ritos - principalmente de natureza iniciática - dados a conhecer por meio de epifanias (1952, p. 88). ${ }^{14}$ Atenta a isso, Marie-George Lonnoy (1986) desenvolveu a questão e demarcou o caráter mistérico da experiência de Aristides e da composição dos Hieroì Lógoi. Desde a época de seu trabalho, esse aspecto da obra tem sido ressaltado (Harrison, 2000; Galli, 2005; Downie, 2008a, 2013; Petsalis-Diomidis, 2010; Guerra, 2014). Assim, assumimos o uso do original grego para identificação da obra e advogamos a seu favor, a fim evitar a perda de minúcias conceituais imprescindíveis para compreendê-la em seu contexto político, social e cultural.

Um segundo ponto a ser enfatizado sobre o título é sua grafia no plural, da qual deriva nossa defesa em sustentar desta maneira todas as referências à obra enquanto uma unidade, como o faz o próprio Aristides não apenas ali (HL 2.9), mas também em um discurso posterior, a Laliá a Asclépio (4.10). ${ }^{15}$ As duas edições do texto grego assim procedem, com

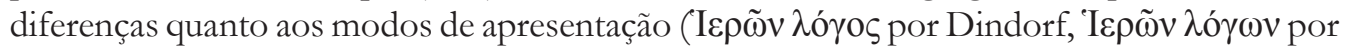
Keil). A conservação do plural é unânime entre os comentadores, à exceção de Janet Downie (2008a, 2008b). O argumento a seu favor leva em consideração o lugar atribuído aos Hieroì Lógoi por Aristides em meio à sua obra maior, a qual inclui outros discursos dedicados e

\footnotetext{
${ }^{14}$ Alguns especialistas no campo dos mistérios também atentam ao uso da expressão, como Walter Burkert (1991) e Alberto Bernabé (2003).

${ }^{15}$ Esta laliá foi declamada em Pérgamo, possivelmente no Asclepeion, por ocasião do festival noturno de 177 (Behr, 1968, p. 130), ou no templo de Zeus Asclépio no ano seguinte, após a visita de Marco Aurélio e Cômodo a Esmirna, quando Aristides solicitou-lhes fundos para a reconstrução da cidade, devastada pelo terremoto de 178 (Cortés Copete, 1999, p. 158). Uma data mais recuada para o encontro com os imperadores, em 176, também é possível, como propôs Laurent Pernot (2008, p. 182).
} 
relacionados a Asclépio, além da mencionada lalia. ${ }^{16}$ A especificidade dos Hieroi Lógoi, a ser pensada como uma unidade particular de discursos, é dada pelo destaque atribuído a eles por Aristides em meio ao conjunto maior de seus discursos e dos outros textos em honra a Asclépio.

Segundo Aristides, os Hieroi Lógoi foram compostos sob as ordens de Asclépio, em agradecimento aos benefícios a ele outorgados e a fim de publicizar os poderes do deus (HL 1.1-4). Como uma narrativa iniciática, esse ex voto textual descreve sonhos de seu autor e intervenções do deus em sua vida. Ali, narrativas oníricas são interligadas a episódios em vigília na medida em que Aristides discursa sobre seu grave estado de saúde e as viagens, tratamentos e regimes prescritos pelo deus e diligentemente cumpridos ao longo de muitos anos. Além desses acontecimentos, destacam-se também suas atividades públicas como orador, também submetidas a Asclépio enquanto parte de uma experiência ao mesmo tempo pedagógica e terapêutica. Tais relatos, muito pouco lineares, são intermeados por imagens e reflexões de grandiosidade, de intimidade e identificação com o deus. Esse deslocamento da esfera humana envaidece Aristides, que relata ser capaz inclusive de interromper terremotos e falar com animais (3.40-42, 50). Esse lugar privilegiado o ampara em sua decisão e insistência em evadir-se dos compromissos públicos que as cidades tentam imputar-lhe $(4.72,88,96$, 101, 102). Ao contrário das antipatias e resistências passíveis de serem causadas aos leitores modernos, os contemporâneos de Aristides não se escandalizam com ele, e parecem admirálo. A Preparaşão Sofística de Frínico, transmitida por Fócio (Biblioteca, 101 a 5-27), aponta nesse sentido, assim como passagens de Galeno (Comentário ao Timeu CMG Suppl. 1, 1934, 33) e de Filóstrato (Vida dos Sofistas, 581). Nos Hieroì Lógoi, Aristides afirma ter por muito tempo se abstido de satisfazer os pedidos de seus amigos, desejosos de verem publicada uma versão organizada de seus discursos, até eventualmente ceder a essas solicitações e às ordens do deus, e envolve-se na composição da obra $(1.2 ; 2.1)$.

Os Hieroì Lógoi constituem uma narrativa autobiográfica na qual o 'eu' é produzido por meio da atribuição de sentidos às experiências oníricas e de iniciação mistérica de seu autor. Desta forma, eles figuram como documento privilegiado em meio a um panorama de variáveis concepções gregas sobre a pessoa. As leituras teórico-metodológicas pertinentes a sua análise levantam questões históricas como as relações entre possibilidade e realidade ${ }^{17} \mathrm{e}$ a

\footnotetext{
${ }^{16}$ Os filhos de Asclépio (discurso 38) é de c. 147, época da estada em Pérgamo (Boulanger, 1923, p. 161; Behr, 1968, p. 59) ou de 154, quando ele vai ao Asclepeion de Epidauro, onde Macáon e Podalírio recebiam culto (Cortés Copete, 1999, p. 99). Ao poço do templo de Asclépio também é da época da estada em Pérgamo (Behr, 1968, p. 105) ou um pouco posterior, entre a cátedra e 153 (Boulanger, 1923, p. 134, 161). Aristides escreveu ainda outros discursos de conteúdo religioso e devocional: Discurso Egípcio (discurso 36), Hino a Atena (37), Hino a Héracles (40), Hino a Dioniso (41), A Zeus (43), Ao Mar Negro (44), A Serápis (45), Ístmico a Poseidon (46) e o Panegírico ao Aqueduto de Pérgamo (53).

${ }_{17}$ As principais referências são Gilles Deleuze (1969), Michel de Certeau (1990) e Marta Mega de Andrade (2004).
} 
circularidade de autoprodução da materialidade homem-mundo. ${ }^{18}$ Em relação a alguns temas caros à História Antiga e aos Estudos Clássicos, os Hieroì Lógoi surgem como um documento apropriado a reflexões sobre a experiência onírica e religiosa no contexto de cidades gregas da Ásia Menor sob domínio romano no século II E.C. ${ }^{19}$ assim como a respeito do corpo, das práticas terapêuticas, ${ }^{20}$ das noções de 'eu' e das narrativas de si. $^{21}$ Por outro lado, destacam-se também em reflexões sobre a peregrinação no mundo antigo, ${ }^{22}$ o exercício da retórica ${ }^{23} \mathrm{e}$ a constituição de redes sociais e identidades nas comunidades imperiais, principalmente no contexto da Segunda Sofística. ${ }^{24}$ Por fim, os Hieroì Lógoi são também parte das discussões sobre os aspectos culturais pelos quais é possível abordar a chamada 'Antiguidade Tardia'. ${ }^{25}$

\section{OS DIÁRIOS ONÍRICOS DE ARISTIDES E SUA RELAÇÃo COM OS HIEROİ LÓGOI}

A ausência de cronologia nos Hieroì Lógoi levou Behr (1968; 1986; 1994) e Festugière (1952) a buscarem estabelecer as datas dos acontecimentos ali narrados. Porém, nesta preocupação há algo de anacrônico, pois Aristides nem podia, nem se dispunha a construir qualquer precisão cronológica na obra (Cortés Copete, 1999, p. 255). Em alguns momentos, ele admite sua incerteza quanto aos detalhes de certos acontecimentos (HL 1.66; 2.54; $3.26,30 ; 4.15,40)$. São muito pouco nítidas as fronteiras entre suas experiências oníricas e em vigilia e, além disso, ele narra acontecimentos bastante recuados no tempo, como as viagens ao Egito e a Roma (HL 4.23, 2.5), ocorridas quase trinta anos antes da escrita da obra. Por outro lado, a discussão sobre a localização dos acontecimentos no tempo sinaliza o problema do processo criativo, das distâncias entre os eventos e entre estes e a própria composição narrativa. Ela é fundamental, por exemplo, para estabelecer a relação entre a obra e os instrumentos mnemônicos de seu autor. Logo ao início das aparições do deus, Aristides recebe de Asclépio a ordem de escrever seus sonhos. Mais tarde, esses registros

\footnotetext{
${ }^{18}$ As principais referências são Heidegger (1950a; 1950b), Julian Thomas (1996), Ian Hodder (2012) e Tim Ingold (2012).

${ }^{19}$ Wilamowitz-Moellendorff (1925), E. R. Dodds (1965), Marie-George Lonnoy (1986), William Harris (2009), Patricia Cox-Miller (1994), Festugière (1952).

${ }^{20}$ Judith Perkins (1995), Brownen Wickkser (2008), Karelisa Hartigan (2009), Alexia Petsalis-Diomidis (2010), Brooke Holmes (2008, 2010), Ido Israelowich (2012), Janet Downie (2013).

${ }^{21}$ Lee Pearcy (1988), Georg Misch (1950), Marie-Henriette Quet (1993), Judith Perkins (1995), Stephen Harrison (2000), Alexia Petsalis-Diomidis (2006), Brooke Holmes (2010), Janet Downie (2013), Lolita Guerra (2014).

${ }^{22}$ Alexia Petsalis-Diomidis (2005, 2010), Marco Galli (2005), Blake Layerle (2009).

${ }^{23}$ Cortés Copete (1995), Maria Mafalda Viana (1997), Luana Quattrocelli (2006), Laurent Pernot (2006a; 2006b), Janet Downie (2013).

${ }^{24}$ André Boulanger (1923), Glen Bowersock (1969), Graham Anderson (1994), Cortés Copete (1995), Marco Galli (2005), Laurent Pernot (2006a), Daniel Richter (2011).

${ }^{25}$ Dodds (1965), Brown (1978), Christopher Jones (1998).
} 
serão acessados por ele como parte da memória materialmente documentada a partir da qual são escritos os Hieroì Lógoi.

Quando adoece durante o inverno de 144 ou 145, Aristides viaja à estação termal de Esmirna, onde, em sonhos, Asclépio o convida ao seu santuário em Pérgamo (HL 2.7). Algum tempo depois dessa primeira epifania, ele viaja para o Asclepeion na companhia de Zósimo, seu tutor, e lá inicia à cátedra de quase dois anos (HL 2.70). Na primeira noite no santuário, em sonhos, Zósimo conversa com Asclépio sobre Aristides. Assim o deus prescreve tratamentos ao orador e também fala de sua obra retórica, chamada por ele de hieroì lógoi. Pela manhã, Aristides ouve a narrativa onírica de Zósimo, e por ordem do deus passa a escrever sobre seus dons e revelações oníricas (HL 2.9). Mais tarde, a expressão conhecida em sonho por seu preceptor será usada por Aristides como título para os Hieroì Lógoi. Ali ele reelabora os relatos dos primeiros registros de forma a dar sentido e tornar pública uma memória apenas parcialmente associada a esses textos, por tanto tempo acumulados de maneira dispersa e fora de ordem:

Agora que se passaram tantos anos e aqueles momentos estão distantes, certas visões oníricas nos obrigam a publicá-los de alguma forma. De fato, devo dizer que desde o princípio o deus me ordenou a registrar meus sonhos, e esta foi precisamente sua primeira ordem. Eu ia compondo o registro por minha própria mão, mas quando não podia fazê-lo, ditava-o. Naquele momento não me ocorreu acrescentar nem em que circunstâncias cada um acontecia, nem suas consequências. Mas eu ficava contente em cumprir minhas obrigações com o deus, em parte, como já disse, pela fraqueza de meu corpo, em parte porque jamais esperei que a providência divina chegasse tão longe. (HL 2.2)

É importante ter em conta duas informações: a ordem de escrever foi a primeira das prescrições de Asclépio, e Aristides não a cumpre desde o início (HL 2.3). Behr (1968, 45 , p. 97) associou este momento ao ano de 166 , quando se inicia o diário contido na obra (HL 1.5-60). Mas essa data ${ }^{26}$ é muito tardia para referir-se à primeira ordem, inclusive por ser posterior à própria cátedra de dois anos em Pérgamo, iniciada entre 146 e 147, quando Aristides passa a cumprir uma série de prescrições determinadas por Asclépio. Além disso, como as antigas anotações estavam desordenadas ou perdidas (HL 2.3ss), Aristides pode ter reproduzido nos Hieroi Lógoi apenas a parte recuperada do diário, cujo início provavelmente é anterior a 166, mas certamente um tanto posterior à ordem de Asclépio, pois admite não a cumprir desde cedo. A prescrição deve ter ocorrido em um momento entre a revelação em Esmirna e estadia em Pérgamo, portanto no intervalo entre 144 e 148. Refletir sobre esta datação nos impede de negligenciar a relação temporal, ao longo de mais de vinte anos de vida, entre os primeiros registros oníricos e a sua efetiva organização e interpretação nos Hieroi Lógoi na década de 170. Aristides está diante de uma interessante condição de

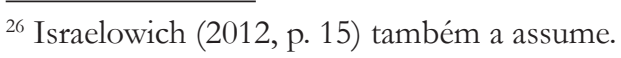


precariedade arquivística: sua saúde o levava a lançar mão de um secretário, os registros são originalmente incompletos quanto ao contexto dos episódios e, ao acessá-los, estão fora de ordem, são por demais extensos, além de parte ter se perdido. Nessas condições, não resta alternativa senão escrever os Hieroi Lógoi como um resumo de acontecimentos muito mais amplos e um registro das principais memórias dos favorecimentos de Asclépio:

Além disso, pesaroso como estava por não ter começado a escrever tudo desde o início, eu era descuidado com os detalhes, às vezes propositadamente, outras não, pois encontrei outros meios de agradecer ao deus. Assim, acredito que o registro tivesse pelo menos trezentas mil linhas. Mas não era fácil acompanhar a narrativa, nem havia precisão cronológica. Além desses inconvenientes, muito se perdeu em desastres de todos os tipos e na confusão em que esteve minha casa naquela época. Resta-me apenas fazer um relato do principal, como o deus me guia a fazer. (HL 2.3ss)

Em seus discursos, Aristides mencionará esses textos como se eles complementassem a narrativa (HL 2.8; 3.26, 30; 4.25). Apesar de não haver qualquer registro deles fora dos Hieroi Lógoi, a historiografia majoritariamente julgou-os verídicos. ${ }^{27} \mathrm{Behr}$ sugeriu inclusive certa identidade entre eles e os Hieroi Lógoi: a comparação aponta que, muito provavelmente, Aristides diverge apenas ligeiramente da fonte primária de seus manuscritos (1968, p. 117). Israelowich por outro lado, empenhou-se em apresentar distinções no interior desse material hipotético. Para ele, Aristides dispunha de um diário médico no qual registrava suas reações aos tratamentos. Esse material teria servido para resgatar informações a respeito das circunstâncias dos sonhos narrados nos Hieroì Lógoi, mas ele não cobriria toda a cronologia dos eventos ali descritos. Além deste, haveria um registro dos próprios sonhos, do qual Aristides não pôde lançar mão quando escreveu os Hieroi Lógoi. Israelowich identifica-o como o extenso material de mais de 300.000 linhas mencionado na obra (2012, p. 16). A hipótese é interessante, mas em nenhum momento é indicada a existência de dois registros de naturezas diferentes. Muito embora assinale que parte do material estivesse perdida, Aristides não afirma qualquer especificidade quanto aos textos indisponíveis. As variações de vocabulário presentes na obra também não amparam a hipótese de Israelowich, pois não há coerência interna nos Hieroi Lógoi que sugira relações entre os diferentes termos e mais de um tipo de registro (Guerra, 2014, 47ss).

Uma hipótese mais interessante sobre os diários é sua relação com a memória de Aristides. Israelowich (2012, p. 17) sugere que, em lugar de lembrar os próprios sonhos, Aristides acessa uma memória dos registros e seu conteúdo. Essa proposta enriquece a discussão sobre as lacunas na documentação acessada por ele quando escreveu os Hieroi Lógoi, além de enfatizar a diferença entre o sonho, sua memória quando acorda e sua elaboração narrativa verbalizada. Israelowich acrescenta mais um nível a essa estratigrafia onírica ao

${ }^{27}$ Boulanger (1923, p. 165, 169); Festugière (1969, p. 121); Dodds (2000, p. 39-40); Saffrey (1986, p. 136, 148); Cortés Copete (1995, p. 70); Holmes (2008, p. 95); Israelowich (2012, p. 16). Schröder (1988) e Pearcy (1988) trabalham no mesmo sentido e amparam artigos inteiros neste pressuposto. 
supor uma memória daquilo que foi escrito, distinta do sonho em si. Essas diferenças são importantes para se pensar os Hieroì Lógoi como uma autobiografia, pois sinalizam a experiência histórica do eu, construído e reelaborado no tempo e por sua própria criação mnemônica e textual de si mesmo. A produção narrativa pode mesmo contribuir para a perda de memória, e essa mesma perda fará parte da composição autobiográfica:

Naquela época (...) sonhei que lia um bom livro que agora não poderia
(me repito) descrever em todos os detalhes. Como poderia lembrar-
me após tanto tempo transcorrido, quando, além disso, compunha
um registro de sonhos que me permitia esquecê-los? (HL 3.30)

O outro lado da discussão sobre os diários é que eles podem não ter existido, mas figurar como um dos instrumentos retóricos dos Hieroì Lógoi, como parte de sua estratégia de convencimento. Aristides, por exemplo, lança mão dos 'diários' para dizer ao seu leitor que, caso deseje saber mais sobre os favores de Asclépio, deve consultá-los ${ }^{28}$ :

Relatar o que daqui em diante se sucedeu não é tarefa para capacidades humanas. Porém, tal e como me propus, devo tentar realizar uma incursão sobre alguns daqueles acontecimentos. Mas, se alguém quiser conhecer com exatidão os favores que recebi do deus, é o momento de buscar entre meus pergaminhos e nos próprios sonhos. (HL 2.8)

Aristides transmite assim a ideia de que suas experiências foram muito mais vastas do que contam os Hieroì Lógoi, e recorre aos registros como comprovação material de sua afirmação, não deixando de esclarecer sua íntima relação com as condições lacunares da narrativa, cujos detalhes foram por vezes esquecidos. Alexia Petsalis-Diomidis contestou a confiança generalizada dos especialistas em relação aos diários e identificou-os como outros textos que foram escritos ou poderiam ter sido escritos e como textos imaginários ou não publicados (2006, p. 196). Os referidos registros teriam assim a função de indicar a distância entre os eventos e a narrativa: os benefícios de Asclépio eram grandiosos demais para acomodaremse à sua exposição resumida nos discursos. Seria preciso buscar nos diários a totalidade das experiências do autor, pois é impossível discursar de maneira a fazer jus aos eventos. Petsalis-Diomidis apontou a eficiência retórica das afirmações de Aristides, amparadas nas condições de composição da obra e dos tópoi literários por ele utilizados (2006, p. 197; 2010, p. 127). Primeiramente, os registros integrais de Aristides nunca foram publicados, e ele mesmo reconhecia sua incompletude, seja em termos de conteúdo, seja pela sua desordem e perda parcial. Além disso, a negativa sobre a possibilidade da narrativa adequada lança mão de uma alegoria literária familiar à sua audiência, amparada em alusões e paralelos

${ }^{28}$ Também devem ser considerados HL 3.26 e 4.25 . 
homéricos. ${ }^{29}$ No prólogo dos Hieroi Lógoi, ele se identifica a Helena, incapaz de narrar todos os feitos de Ulisses:

Tenho a impressão de que vou compor minha obra como a Helena de Homero, pois de fato ela disse que não repetiria tudo o que o incansável Odissen forjou ${ }^{30}$ mas depois de selecionar apenas uma ação, creio eu, contou-a a Telêmaco e Menelau. De minha parte, eu também não quero contar todas as façanhas do Salvador, das quais desfrutei até o dia de hoje, e de forma alguma acrescentaria aquele verso homérico - nem tendo dez bocas, dez. línguas, voz inquebrável, peito brônzeo, eu saberia dizer- ${ }^{31}$ pois isso ainda seria pouco. Ainda que superasse todas as capacidades humanas, tanto em voz quanto em sabedoria, nem assim me aproximaria delas. (HL 1.1)

O uso das citações homéricas induz a audiência a atribuir veracidade aos discursos, pois a remete ao disseminado lugar-comum de que certas experiências, por sua grandiosidade, não podem ser abarcadas pela fala humana. O convite pela busca, entre seus diários, de mais detalhes sobre sua narrativa (HL 2.8) vai na mesma direção, pois dá a impressão de que o relato pode ser verificado e confirmado. Não importa tanto se os diários existiram ou não. Nos Hieroi Lógoi, eles são recriados como instrumento de convencimento da audiência sobre a seriedade da narrativa de Aristides e a grandiosidade do poder de Asclépio, assim cumprindo sua função devocional, mas sem perder seu caráter autobiográfico.

\section{CONCLUSÃo}

O debate em torno da composição dos Hieroi Lógoi, o qual acompanha o movimento editorial em torno deles, sinaliza a necessidade de se refletir sobre seu caráter documental desde a historiografia e as edições hoje em circulação até seus processos de criação e as possíveis fontes utilizadas por Aristides para produzi-lo e atribuir-lhe veracidade. As lembranças das próprias experiências, de seu registro narrativo posterior, de sua reelaboração discursiva nos Hieroi Lógoi e a transmissão do texto na modernidade compõem níveis materiais e imateriais da memória de Aristides. Eles devem ser levados em consideração quando nos debruçamos sobre a obra e sua identidade como autobiografia e aretologia, pois encontram uma função retórica fundamental à sua própria transmissão. Também devemos sinalizar a possibilidade de Aristides ter construído para si boa parte da memória relativa à composição dos Hieroi Lógoi, não apenas, naturalmente, quanto aos acontecimentos extraordinários ali descritos mas

\footnotetext{
${ }^{29}$ Os protestos de Aristides sobre sua incapacidade narrativa são bastante frequentes (HL 1.2; 2.1, 8, 10, 18, 22, 32, 80; 3.6; 17.30 e 4.15, 38, 70, 80). A obra apresenta mais de 250 citações da Ilíada e quase 100 da Odisseia, e são cerca de 150 invocações ao nome Homero em toda obra de Aristides (Cortés Copete, 1995, p. 9). Algumas das alusões homéricas são encontradas em HL 1.1; 2.42, 58, 60 e 5.44.

${ }^{30}$ Odisseia, 4. 240-243, segundo a tradução de Trajano Vieira (2011).

${ }^{31}$ Ilíada, 2. 488-493, tradução de Haroldo de Campos (2010).
} 
também quanto aos próprios diários, suas características e seu conteúdo. É importante ter em conta a distância entre os eventos e a narrativa, mas isso não implica assumir ou negar a existência dos registros mais antigos. Acreditamos ser produtivo encaminhar a discussão sobre os Hieroi Lógoi em direção ao problema da memória, não apenas de Aristides e seus interesses particulares mas também a de um contexto maior de fragmentos de informações pessoais associados a convenções literárias e de produções narrativas de 'vidas' que não deixam de ter algo de fictício. A criação de si não abre mão desses instrumentos pelos quais a própria fala faz-se reconhecer e afirmar, documentados, guardados, perdidos e recuperados pela memória.

\section{REFERÊNCIAS}

\section{DocumentaÇão}

AELIUS ARISTIDE. Discours sacrés. Rêve, religion, médecine au II siècle après J.C. Intr. et trad. par André-Jean Festugière. Notes par Henri-Dominique Saffrey. Paris: Macula, 1986.

AELIUS ARISTIDES. Aelius Aristides and the Sacred Tales. Trans. Charles Behr. Amsterdam: Adolf Hakkert, 1968.

AELIUS ARISTIDES. Die Romrede des Aelius Aristides. Herausgegeben, übersetzt und mit Erlaüterungen versehen von Richard Klein. Darmstadt: Wissenschaftliche Buchgesellschaft, 1981.

AELIUS ARISTIDES. Heilige Berichte. Einleitung, deutsche Übersetzung und Kommentar von Otto Schröder. Heidelberg: Carl Winter, 1986.

AELIUS ARISTIDES. Orationes. Wilhelm Dindorf (ed). Leipzig: Weidmann, 1829.

AELIUS ARISTIDES. The Complete Works. Trans. Charles Behr. Leiden: Brill, 1981-1986.

AELII ARISTIDIS Quae supersunt omnia. Bruno Keil (ed.). Berlin: Weidmann, 1898.

AELII ARISTIDIS Opera quae exstant omnia. Fridericus Waltharius Lenz et Carolus Allison Behr (ed). Leiden: Brill, 1976.

EDELSTEIN, Emma; EDELSTEIN, Ludwig. Asclepius. Collection and interpretation of the testimonies. Baltimore: Johns Hopkins University Press, 1998.

ELIO ARISTIDES. Discorsi Sacri. A cura di Salvatore Nicosia. Milano: Adelphi, 2008 [1984].

ELIO ARISTIDES. Discursos sagrados. LUCIANO DE SAMOSATA. Sobre la muerte de peregrino. Alejandro o el falso poeta. Edición de María Concepción Giner Soría. Madrid: Akal, 1989.

ELIO ARISTIDES. Discursos. Vol. V. Intr., trad. y notas de Juan Manuel Cortés Copete. Madrid: Gredos, 1999.

FOZIO. Biblioteca. Trad. Giuseppe Compagnoni. Milano: G. Silvestri, 1836. 
GALENI In Platonis Timaeum commentarii fragmenta. Collegit disposuit explicavit H. O. Schröder. Leipzig: Teubner, 1934.

HOMERO. Odisseia. Tradução, posfácio e notas de Trajano Vieira. Ensaio de Italo Calvino. São Paulo: Ed. 34, 2011.

HOMERO. Iliada. Tradução de Haroldo de Campos. Introdução e organização de Trajano Vieira. São Paulo: Arx, 2003.

PHILOSTRATUS. The Lives of the Sophists. With an English translation by Wilmer Cave Wright. London: William Heinemann, 1922.

\section{BiBLIOGRAFIA}

ANDERSON, Graham. Sage, saint and sophist. Holy men and their associates in the early Roman Empire. New York: Routledge, 1994.

ANDRADE, Marta Mega de. O tempo e os outros: ensaios sobre História e Alteridade. Boletim do CPA. Campinas, n. 17, jan. / jun. 2004.

BERNABÉ, Alberto. Hieros logos. Poesia órfica sobre os deuses, a alma e o além. São Paulo: Paulus, 2012 [2003].

BEHR, Charles Allison. Studies in the biography of Aelius Aristides. Aufstieg und Niedergang der Römischen Welt. n. II, v. 34.22, 1994, p. 1140-1223.

BOMPAIRE, Jacques. Quatre styles d'autobiographie au $\mathrm{II}^{\mathrm{e}}$ siècle après J.-C. In: BASLEZ, Marie-Françoise; HOFFMANN, Philippe; PERNOT, Laurent. L'invention de l'autobiographie d'Hésiode à Saint Augustin. Paris: École Normale Supérieure 1993, p. 199-209.

BOULANGER, André. Aelius Aristides et la sophistique dans la province d'A sie au IIe Siècle de Notre Ëre. Paris: De Boccard, 1923.

BROWN, Peter. The making of Late Antiquity. Cambridge: Harvard University Press, 1993 [1978].

BURKERT, Walter. Antigos Cultos de Mistério. São Paulo: EdUSP, 1991.

CERTEAU, Michel de. A Invenção do Cotidiano: artes de fazerer. Petrópolis: Vozes, 2008 [1990].

CORTÉS COPETE, Juan Manuel. Elio Aristides. Un sofista griego en el Imperio Romano. Madrid: Ediciones Clásicas, 1995.

COX-MILLER, Patricia. Dreams in Late Antiquity. Studies in the imagination of a culture. New Jersey: Princeton University Press, 1994.

DELEUZE, Gilles. Lógica do Sentido. São Paulo: Perspectiva, 2009 [1969].

DIBDIN, Thomas. An introduction to the knowledge of rare and valuable editions of the Greek and Latin Classics. London: Longman, 1808. 
DODDS, Eric Robertson. Pagan and Christian in an age of anxiety. Cambridge: Cambridge University Press, 1965.

DOWNIE, Janet. At the limits of art. A literary study of Aelius Aristides' Hieroi Logoi. Oxford: Oxford University Press, 2013.

DOWNIE, Janet. Professing illness: healing narrative and rhetorical self-presentation in Aelius Aristides' Hieroi Logoi. Dissertation - Department of Classics, University of Chicago, Chicago, 2008a.

DOWNIE, Janet. Proper pleasures: bathing and oratory in Aelius Aristides' Hieros Logos I and Oration 33. In: HOLMES, Brooke; HARRIS, William. Aelius Aristides between Greece, Rome and the gods. Leiden: Brill, 2008b, p.115-130.

EAKIN, Paul John. Fictions in autobiography: studies in the art of self-invention. New Jersey: Princeton University Press, 1985.

FESTUGIÈRE, André-Jean. Personal religion among the Greeks. Berkeley: University of California Press, 1954.

GALLI, Marco. Pilgrimage as elite habitus: educated pilgrims in sacred landscape during the Second Sophistic. In: ELSNER, Jaś; RUTHERFORD, Ian. Pilgrimage in Graeco-Roman and early christian Antiquity. Oxford: Oxford University Press, 2005, p. 253-290.

GUERRA, Lolita Guimarães. Noturno Vagar: o eu mortal imortal nos Hieroì Lógoi de Élio Aristides. Tese (Doutorado em História - área História Cultural) - Programa de Pós-Gradução em História, Instituto de Filosofia e Ciências Humanas, Universidade Estadual de Campinas, Campinas, 2014.

HARRIS, William. Dreams and Experience in Classical Antiquity. Cambridge: Harvard University Press, 2009.

HARRISON, Stephen. Apuleios, Aelius Aristides and religious autobiography. Ancient Narrative, v. 1, p. 245-259, 2000.

HARTIGAN, Karelisa. Performance and Cure: drama and healing in Ancient Greece and Contemporary America. London: Duckworth, 2009.

HEIDEGGER, Martin. A origem da obra de arte. Lisboa: Edições 70, 2010 [1950a].

HEIDEGGER, Martin. A Coisa. In: Ensaios e conferências. Petrópolis: Vozes, 2002 [1950b].

HODDER, Ian. Entangled. An archaeology of the relationships between humans and things. Malden: Wiley-Blackwell, 2012.

HORSTMANSHOFF, Manfred. Aelius Aristides: a suitable case for treatment. In: BORG, Barbara. Paideia: the world of the Second Sophistic. Berlin: W. de Gruyter, 2004, p. 277-290.

HOLMES, Brooke. Aelius Aristides' Illegible Body. In: HOLMES, Brooke; HARRIS, William. Aelius Aristides between Greece, Rome and the gods. Leiden: Brill, 2008, p. 82-113.

HOLMES, Brooke. The symptom and the subject. The emergence of the physical body in ancient Greece. New Jersey: Princeton University Press, 2010. 
HOLMES, Brooke; HARRIS, William. Aelius Aristides between Greece, Rome and the gods. Leiden: Brill, 2008.

INGOLD, Tim. Being alive. London: Routledge, 2011.

INGOLD, Tim. Trazendo as coisas de volta à vida: emaranhamentos criativos num mundo de materiais. Horizontes antropológicos. Porto Alegre, v. 18, n. 37, p. 25-44, 2012.

ISRAELOWICH, Ido. Society, medicine and religion in the Sacred Tales of Aelius Aristides. Leiden: Brill, 2012.

JAEGER, Werner. Review: A History of Autobiography in Antiquity, by Georg Misch. Speculum, v. 28, n. 2, p. 405-410, 1953.

JONES, Christopher P. Aelius Aristides and the Asklepieion. In: KOESTER, Helmut. Pergamon: Citadel of the Gods. Archaeological record, literary description, and religious development. Harrisburg: Trinity, 1998, p. 63-76.

LAYERLE, Blake. Mobility and the traces of empire. In: ROUSSEAU, Philip; RAITHEL, Jutta. A Companion to Late Antiquity. Malden: Blackwell, 2009, p. 110-123.

LEJEUNE, Philippe. O pacto autobiográfico. De Rousseau à internet. Belo Horizonte: UFMG, 2008 [1996].

LEVI, Giovanni. Usos da biografia. In: FERREIRA, Marieta; AMADO, Janaína. Usos \& abusos da história oral. Rio de Janeiro: FGV, 1996 [1989], p. 167-182.

LONNOY, Marie-George. L'éxpérience initiatique d'Aelius Aristide. Bulletin de l'Association Guillaume Budé, v. 1, n. 1, p. 41-50, mars 1986.

MISCH, Georg. A History of Autobiography in Antiquity. London: Routledge, 1950 [1907].

PEARCY, Lee. Theme, dream and narrative: reading the Sacred Tales of Aelius Aristides. Transactions of the American Philological Association, v. 118, p. 377-91, 1988.

PERKINS, Judith. The 'Self' as sufferer. The Harvard Theological Review, v. 85, n. 3, p. 245-272, 1992.

PERKINS, Judith. The Suffering Self. Pain and narrative representation in the early christian era. New York: Routledge, 1995.

PERNOT, Laurent. Aelius Aristides and Rome. In: HOLMES, Brooke; HARRIS, William. Aelius Aristides between Greece, Rome and the gods. Leiden: Brill, 2008, p. 175-201.

PERNOT, Laurent. La Seconde Sophistique et l'Antiquité tardive. Classica. Revista Brasileira de Estudos Clássicos, v. 19, n. 1, p. 30-43, 2006 a.

PERNOT, Laurent. The Rhetoric of Religion. Rhetorica, v. 24, n. 3, p. 235-254, 2006b.

PETSALIS-DIOMIDIS, Alexia. The body in the landscape: Aristides' corpus in light of The Sacred tales. In: HOLMES, Brooke; HARRIS, William. Aelius Aristides between Greece, Rome and the Gods. Leiden: Brill, 2008, p.131-150. 
PETSALIS-DIOMIDIS, Alexia. Truly Beyond Wonders. Aelius Aristides and the Cult of Asklepios. Oxford: Oxford University Press, 2010.

PETSALIS-DIOMIDIS, Alexia. Sacred writing, sacred reading: the function of Aelius Aristides' self-presentation as author in the Sacred Tales. In: McGING, Brian; MOSSMAN, Judith. The limits of ancient biography. Swansea: The Classical Press of Wales, 2006, p. 193-211.

QUATTROCELLI, Luana. Aelius Aristides' reception at Byzantium: the case of Arethas. In: HARRIS, William; HOLMES, Brooke. Aelius Aristides between Greece, Rome, and the gods. Leiden: Brill, 2008, p. 279-293.

QUATTROCELLI, Luana. Il pubblico dei Discorsi Sacri di Elio Aristide. In: ABBAMONTE, Giancarlo; MILETTI, Lorenzo; SPINA, Luigi (a cura di). Discorsi alla prova. Atti del Quinto Colloquio Italo-Francese "Discorsi pronunciati, discorsi ascoltati: contesti di eloquenza tra Grecia, Roma ed Europa”. Napoli: S. Maria di Castellabate, 21-23 settembre 2006, p. 259-278.

QUET, Marie-Henriette. Parler de soi pour louer son dieu: le cas d'Aelius Aristide. In: BASLEZ, Marie Françoise; HOFFMANN, Philippe; PERNOT, Laurent. L'invention de l'Autobiographie d'Hésiode à Saint Augustine. Paris: École Normale Supérieure, 1993, p. 211-251.

RICHTER, Daniel. Cosmopolis. Imagining community in late classical Athens and the early Roman Empire. Oxford: Oxford University Press, 2011.

ROBERT, Fabrice. Enquête sur la présence d'Aelius Aristide et son oeuvre dans la littérature grecque du $\mathrm{II}^{\mathrm{e}}$ au $\mathrm{XV}^{\mathrm{e}}$ siècle de notre ère. Anabases. Traditions et réceptions de l'Antiquité, v. 10, p. 141-160, 2009.

THOMAS, Julian. Time, culture and identity. London: Routledge, 1996.

VIANA, Maria Mafalda. Élio Aristides e o Discurso do Elogio. Tradução e comentário do Hino a Zeus e Hino a Asclépio. Dissertação (Mestrado em Literatura Grega) - Faculdade de Letras da Universidade de Lisboa, Lisboa, 1997.

WILAMOWITZ-MOELLENDORFF, Ulrich von. Der Rhetor Aristides. In: Sitzungsberichte der Preussiscbten Akademie der Wissenschaften. Berlin, 1925, p. 333-353.

WICKKSER, Bronwen. Askelepios, Medicine and the Politics of Healing in Fifth-Century Greece. Baltimore: Johns Hopkins University Press, 2008.

WILSON, Nigel. Maximo Planudes, the Codex Laurentianus 60.8 and other Aristidean manuscripts. Revue des Études Grecques, v. 122, p. 253-261, 2009.

Recebido em 2 de abril de 2017 Aprovado em 11 de junho de 2017 